\title{
The Conservation Status and Utilization Strategies of Historic Buildings in Baoding, Hebei
}

\author{
Ziyang Wang ${ }^{\text {a, }}{ }^{*}$, Haimei $\mathrm{Li}^{\mathrm{b}}$ \\ Department of Law and Political Science, North China Electric Power University (Baoding), Hebei, \\ 071066, China \\ a, *821066287@qq.com, b 2625346624@qq.com
}

\begin{abstract}
Baoding of Hebei province is a national historical and cultural city with a history of more than 3,000 years. There are abundant cultural relics and historic sites in Baoding with high historical and cultural value. However, due to the rapid development of urbanization and the changes of the natural environment, coupled with the lack of experience and effort in the protection, historical buildings in Baoding have gradually been damaged or even disappeared in the course of history. In view of this, this research combines empirical investigations and in-depth interviews, and analyzes the problems and utilization strategies in the protection of historic buildings in Baoding.
\end{abstract}

Keywords: Historic Buildings; Protection and Utilization; Culture; Strategies.

\section{Introduction}

Since the 18th National Congress of the Communist Party of China, the Party Central Committee with Comrade Xi Jinping at its core has attached great importance to building a cultural power and vigorously promoted the excellent traditional Chinese culture. As an important part of Chinese excellent traditional culture, historical buildings are important cultural heritages. Baoding has 17 national-level and 115 provincial-level cultural relics protection units, whose number of cultural relics and historic sites ranks first in Hebei Province. The country was established as the second batch of national historical and cultural cities.

Beginning in the 1990s, the government has launched a large-scale transformation of the old city. In this process, it blindly pursued speed, causing most of the historical buildings in the city to be overthrown, therefore the area of the historic district was rapidly reduced and fragmented. There are only two or three historical blocks in Baoding now. There is no time to delay necessary protection.

\section{Analysis of the Straits Faced by the Protection of Historic Buildings in Baoding}

\subsection{Economic Straits}

Mainly relying on the government's public property investment, there is a big gap in capital investment in the protection of historical buildings at present. At the same time, the investment of government funds has a certain degree of selectivity, which concentrates on the more famous historical buildings such as Baoding Museum of Zhili Govern-general's Office, Gulian lotus pond, and Ran Zhuang tunnel site. As a result, the protection and development of these historical buildings are also relatively better. While those less well-known historical buildings such as Guanyin Temple, Daci Pavilion, Catholic Church have very little funding. Problems like the long lack of maintenance funds and the break of the funding chain during construction also become an obstacle restricting development. Moreover, the completeness of the building's internal infrastructure and the improvement of the quality of public services can to a large extent attract more passenger flow. Therefore, the tourism industry also needs support from other service industries. 


\subsection{Management Straits}

\subsubsection{Insufficient Supervision}

Relevant regulatory agencies are disorganized, leading to overlapping management. There are also phenomena of bloated departments, greed for completeness, and unclear powers and responsibilities within the management institutions. Therefore, it is necessary to smooth the supervision and management functions. The main protection unit of historic buildings in Baoding are the Cultural Relics Management Office and the Museum Office subordinated to Baoding Culture, Radio, Television and Tourism Administration. The Cultural Relics Management Office is mainly responsible for the management of historic buildings designated as cultural relics, while the Museum Office is mainly responsible for the historic buildings of museum type. Some ancient buildings, such as those along the Fu River, are neither museums nor cultural relics, but they have historical value. Such buildings are management blind spots and reflects the ambiguity of rights and responsibilities.

\subsubsection{Weak Policy Implementation}

Because of the built-in problems of the relevant supervision and management institutions, the power of the departments is limited, and it is easy to appear that the policy implementation is not strong enough. Moreover, the existence of some situations like buck-passing and interest entanglement have restricted the enforcement of historical building protection to a certain extent. For instance, the repair work of the Chenghuang Temple involves Baoding Culture, Radio, Television and Tourism Administration, Baoding Development and Reform Commission, and Baoding Bureau of land and resources. It also involves the interest bodies like surrounding residents and real estate developers. There are certain interest entanglements, followed with the impact of the epidemic, thus the maintenance of Chenghuang Temple has not been completed for many years.

\subsection{Cultural Straits}

\subsubsection{Loss of Original Historical Features}

Due to the fact of old age and man-made sabotage, many historical buildings have more or less problems such as structural damage, partial missing or collapse, and weathering and fading of the surface. Baoding Government has made comprehensive coverage of the repair and maintenance of historical buildings, from large houses to small temples. However, due to the lack of strict supervision during the transformation of the old city, inadequate planning and the absence of complete information, the lack of financial and technical support and other reasons, many historical buildings have lost their original historical features, and some are even "repaired as new", which looks like a giant "forgery".

\subsubsection{Absence of Historical and Cultural Connotation}

In addition to precious unique style of historic buildings which is different from modern architectures, the profound historical and cultural deposits they carry are their soul. Historic buildings reflect the changes of the times, record the historical context of national development, and carry national memory and even national spirit. Their appearance may be magnificent or exquisite, but the historical and cultural value they inherent is what we should dig and learn deeper. This is the foundation of our cultural self-confidence and cultural soft power. Unfortunately, Baoding still needs to work hard in the historical and cultural excavation of historic buildings. Because it only focuses on the protection and utilization of large-scale historic buildings with profound historical and cultural heritage, such as the Baoding Museum of Zhili Govern-general's Office, Gulian lotus pond. Some other historic buildings smaller in scale were buried or abandoned. Historic buildings are not only ornaments, only by deep exploration of the historical and cultural heritage behind them can better bring out their multicultural value of education and inspiration. 
Volume 14 (2021)

\subsection{Institutional Straits}

Many problems have arisen because of a lack of guidance and planning for the protection and development of historic buildings, and no scientific experience as a guide for action. Firstly, the plan lacks integrity and continuity. During our visit to West Street, we learned that due to frequent changes of the mayor, the urban planning has varied while the implementation of new policy is not in place and in effect, and the original construction progress has thus slowed down. Secondly, the plan lacks originality. The landscape planning's of many historic buildings are almost the same, losing the original cultural characteristics of respective buildings. Thirdly, the plan lacks sustainability. Most of the historic buildings adopt relatively low-level tourism forms, attracting passenger flow only through the appearance of the buildings, instead of digging the historical and cultural connotation of the building itself from the root, which leads to the fact that tourists do not really understand the building.

\section{Management Suggestions for the Protection of Historic Buildings in Baoding}

\subsection{Expand Participants and Establish Multiple Governance Mechanisms}

The multi-cooperative multi-center historical building protection model is demand-oriented, providing more professional and feasible historic building protection based on the actual situation of different historical buildings. The multiple cooperation model establishes a partnership between the government, the market, and social organizations, and should fully introduce a mechanism for residents to discuss and build together. As a link for the protection of historic buildings, the government should on the one hand make full use of market mechanisms, and on the other introduces social organizations into professional protection. The market plays a decisive role in integrating resources from all parties, and introducing running water to enhance the protection of historic buildings. While social organizations can organize forces to clean historic buildings, in addition, they can act as a third-party team to evaluate and supervise the protection and restoration of historic buildings.

\subsection{Broaden Financing Channels in an All-round Way to Supplement Government Investment}

Increasing the government's financial investment, taking government financial investment as the leading factor, and broadening the financing channels in an All-round way is a strong driving force for the protection and development of historic buildings in Baoding. Seize the opportunity of national financial policy adjustment, make good use of the policies, and effectively transform the policies into ideas for planning work and practical measures to promote work. At the same time, strengthen cooperation with financial institutions in the city, combine central policies with local resources, innovate financing methods, expand financing scale, build financing platforms, and effectively solve the financial problems that restrict the protection and development of historic buildings in Baoding.

\subsection{Strengthen Infrastructure Construction and Improve the Quality of Public Services}

Optimize public services by strengthening the construction and transformation of public infrastructures. The local area should improve infrastructures of historic buildings, such as laying concrete roads, improving the environment of public toilets, optimizing the internal environment and focusing on cleanliness, adding signs, display boards and other supporting service facilities, and improving the infrastructure conditions of the buildings for tourists to provide a good service experience.

\subsection{Strengthening Construction of Connotation and Improve Reputation and Influence}

Relevant government departments should strengthen the awareness of using historic buildings to tell Baoding stories and Chinese stories well. Strengthen the innovation of historical and cultural forms of historic building tourism, and improve the quality of traditional display forms such as 
physical display and tour description. On this basis, innovate historical and cultural display forms, learn from the successful experience of other regions, and develop such forms as scene restoration, immersive experience, cultural and creative products, live-demonstration and other forms. At the same time, pay attention to the role of the Internet in information dissemination, fill in the voids in entry content, improve the lack of map addresses and other problems, and use a variety of network software and new media, such as Weibo, WeChat official account, Xiaohongshu, Meituan, etc., to grasp the hotspots of the flow, strengthen the propaganda of historic buildings and the historical culture contained in them.

\subsection{Use Publicity and Education to Enhance Public Awareness of Protection}

Make full use of various means of publicity and education to carry out relevant publicity activities near representative historic buildings on holidays. Develop new methods to enhance the flexibility, interest and learnability of propaganda and education. Strengthen the publicity and education of cultural relics protection in public places, communities, and schools. Provide relevant public lecture to residents around historic buildings, if possible, enhance the protection awareness of the public and drive the whole society to increase the protection awareness of historic buildings.

\section{References}

[1] Enmao Qiao, Qi Ding, Dawei Shang, Zhiguo Hou. Analysis and Interpretation of the Protection of Ancient Buildings in Urban Design [J]. The Frontiers of Society, Science and Technology, 2020, 2 (8).

[2] Arto Ignacio, Gallego Rafael, Cifuentes Héctor, Puertas Esther, Gutiérrez-Carrillo M. L. Fracture behavior of rammed earth in historic buildings[J]. Construction and Building Materials,2021,289.

[3] WU Xiaohui. Experience and Inspiration of Protection and Utilization of Historic Buildings in Germany [J]. China Ancient City,2020(12):41-48.

[4] Wu Cong. Research on Protection and Utilization Strategies of Historical Architectures from the Perspective of Cultural Inheritance --A Case of Hanyang District in Wuhan[J]. Urbanism and Architecture, 2019, 16 (03):122-124.

[5] Wanf Shan. The Experience and Inspiration of the Protection of Cultural Heritage in France and Italy[J]. Journal of North China Electric Power University (social sciences),2015(02):74-79.

[6] Chengya Zhang, Yubo Gao, Enze Duan. The Influence of Environment on the Settlement of Historic Buildings in China[J]. KSCE Journal of Civil Engineering,2021(prepublish).

[7] Chen Lier. Tradition and Relive: 1taly Museum in Historic Buildings[J]. Journal of Nanping Teachers College, 2016, 35(02):50-54. 